\title{
Possible Role of MHD Waves in Heating the Solar Corona
}

\author{
B.N. Dwivedi · V.S. Pandey
}

Published online: 15 April 2009

(C) Springer Science+Business Media B.V. 2009

Erratum to: Solar Phys (2003) 216: 59-77

DOI 10.1023/A:1026125928058

This paper has been retracted and should not be cited as it contains uncited, previously published material as discussed in J.A. Klimchuk, L.J. Porter, and P.A. Sturrock, Solar Physics 221, 47, 2004. B.N. Dwivedi and V.S. Pandey apologize to L.J. Porter, J.A. Klimchuk, and P.A. Sturrock, and to the scientific community.

The online version of the original article can be found under doi:10.1023/A:1026125928058.

B.N. Dwivedi $(\varangle)$. V.S. Pandey

Department of Applied Physics, Institute of Technology, Banaras Hindu University, Varanasi, 221005 , India

e-mail: bholadwivedi@yahoo.com 